\title{
Distribution of sulfur isotopes in the Ryusei vein of the Akenobe mine, Hyogo Prefecture, Japan
}

\author{
MASAHIRO YAMAMOTO \\ Department of Earth Science, Faculty of Science, \\ Okayama University, Okayama 700, Japan
}

(Received March 6, 1974)

\begin{abstract}
Sulfide samples (mostly chalcopyrite with some sphalerite and bornite) from the Ryusei vein of the Akenobe mine exhibit a narrow spread in $\delta^{34} \mathrm{~S}$ value ranging from -4.4 to $-0.4 \%$. The range is lower than those of other Japanese sulfide deposits so far studied. The frequency diagram of $\delta^{34} \mathrm{~S}$ values for chalcopyrite indicates that the ${ }^{34} \mathrm{~S}$ distribution is bimodal; one peak at -3.0 to $-2.5 \%$ and the other at -1.5 to $-0.5 \%$. This suggests that chalcopyrite in the Ryusei vein was formed in at least two different stages of mineralization.

Of 9 sphalerite-chalcopyrite pairs studied (including 2 pairs from different veins), 8 pairs are isotopically in disequilibrium; sphalerite is up to $2.7 \%$ lighter than coexisting chalcopyrite.

From the isotopic and chemical equilibrium relationship between the aqueous and mineral species of the $\mathrm{Cu}-\mathrm{Fe}-\mathrm{S}-\mathrm{O}$ system, $\delta^{34} \mathrm{~S}$ values of the ore-forming solutions were speculated to be rather similar to those of chalcopyrite $(0 \sim-5 \%)$.
\end{abstract}

\section{INTRODUCTION}

We have been studying the distribution of sulfur isotopes in various types of Japanese sulfide deposits in order to understand geochemical behaviors of sulfur isotopes in ore-forming processes. The results on the Yanahara massive pyritic ore deposits of Kieslager-type (Yамамото et al., 1968), the Hitachi cupriferous pyrite deposits of Kieslager-type (Yамамото and KASE, 1973), and the Iwami Kuroko deposits (Yамамото, 1974) have been reported.

In the present paper the sulfur isotope ratios of sulfide minerals from the Ryusei vein of the Akenobe mine, Hyogo Prefecture, Japan, will be reported and discussed. The deposits are well known as the representative of xenothermal deposits. The study was initiated with the purpose of revealing the distribution of sulfur isotopes within a single vein and sulfur isotopic fractionation among different sulfide minerals within single hand specimens. 


\section{Outline of the Deposits of the Akenobe Mine}

The Akenobe mine is situated in Hyogo Prefecture, Japan, and is producing copper, zinc, lead, tin and tungsten. The geology and ore deposits of the mining area have been described in detail by SAIGUSA (1958), AbE (1963), MURAOKA and IKEDA (1968), IKEDA (1970) and KoJIMA and AsADA (1973).

The mining area of $4 \sim 5 \mathrm{~km}$ square is composed mainly of Paleozoic green rocks (basic lava and its tuff) and slate (KoJIMA and ASADA, 1973). Sedimentary rocks are intruded here and there by Triassic meta-diorite and meta-gabbro. Granite porphyry of the same age is exposed in the western part of the area (KoJima and AsadA, 1973). Andesitic, rhyolitic, and breccia dikes also occur in the area. Recent age determinations of the rhyolitic dikes suggest that most dikes are of Late Cretaceous or Early Tertiary age (ISHIHARA and SHIBATA, 1972).

The deposits are of xenothermal type. They consist of about a hundred polymetallic composite veins traversing both sedimentary and igneous rocks. Main ore minerals are chalcopyrite, sphalerite, bornite, galena, magnetite, cassiterite and wolframite with subordinate amounts of pyrite, pyrrhotite and others (MURAOKA and IKEDA, 1968). Gangues are quartz, fluorite, siderite, calcite, chlorite and others (MURAOKA and IKEDA, 1968).

In recent years many workers have considered that the deposits are genetically related to Late Cretaceous or Early Tertiary granite which crops out to the northeast of the mining area (e.g. Imai et al., 1972; Ishinara and Shibata, 1972; KoJima and ASADA, 1973). Nakamura and Hunahashi (1970), however, has a different view that the mineralization is related to Neogene volcanic activities.

The Ryusei vein The Ryusei vein is located at the southern part of the mining area which belongs to the Cu-rich zone (IKEDA, 1970). Host rocks are diorite with some slate in the upper part of the vein and green rocks in the lower part (Fig.1, after MuRAOKA and IKEDA, 1968).

Main ore minerals are chalcopyrite, sphalerite, bornite, magnetite and cassiterite with minor amounts of wolframite, chalcocite, and other sulfides. Of these, chalcopyrite is by far the most abundant. Iron sulfides such as pyrite and pyrrhotite are absent or rare. Quartz is the principal gangue mineral with subordinate amounts of chlorite, siderite and others.

In most places the vein is composed of massive chalcopyrite in bands and irregular impregnations, associated with quartz, magnetite, sphalerite, bornite and others. Sphalerite occurs in rims around chalcopyrite grains, in aggregates intimately associated with chalcopyrite, or in separate bands. Sphalerite always has chalcopyrite blebs or veinlets in it. Bornite is found generally as sporadic fine inclusions in chalcopyrite, but in some places as massive aggregates associated with chalcopyrite and magnetite. Magnetite occurs mostly as fine granules in chalcopyrite and quartz, 
or massive aggregates with laminated structure disseminated by chalcopyrite. Cassiterite occurs generally as finne granules in quartz and chalcopyrite. It is often concentrated around chalcopyrite and wall rock fragments in quartz veins.

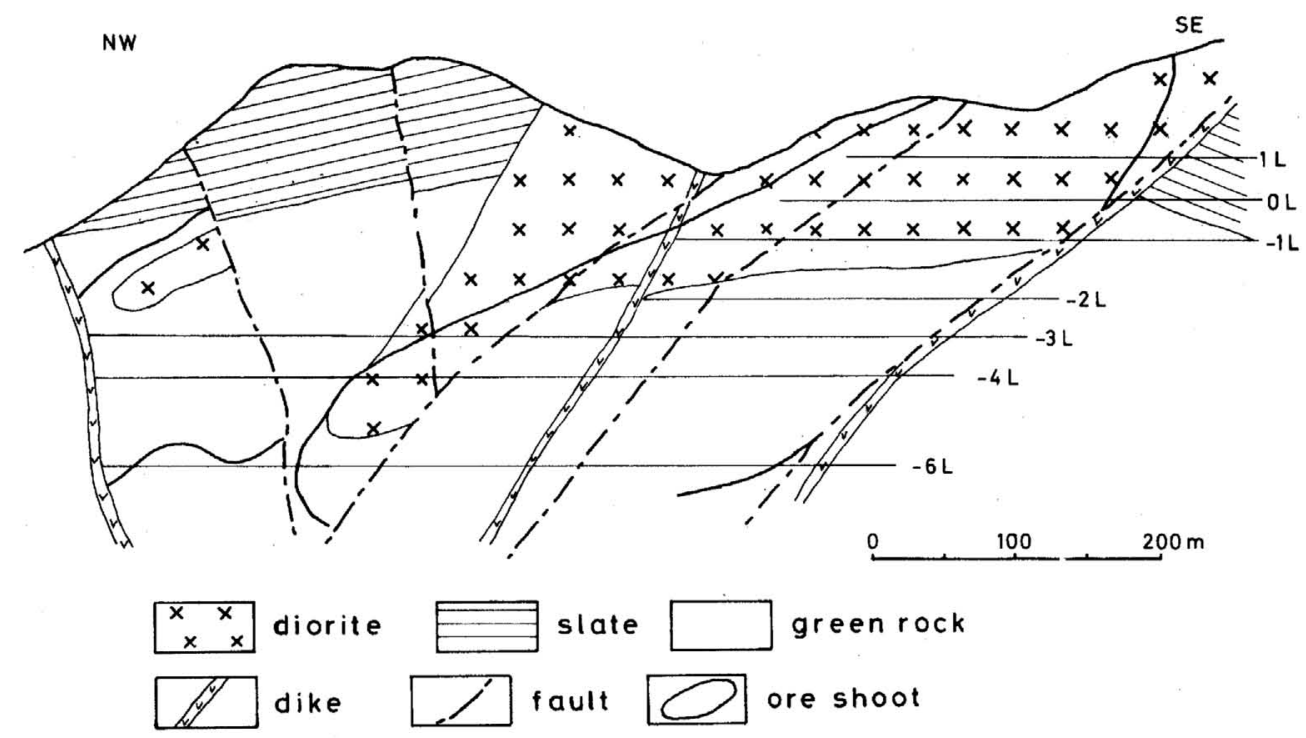

Fig.1. Vertical section of the Ryusei vein (after MURAOKA and IKEDA, 1968).

\section{EXPERIMENTAL}

Samples Samples were collected from the levels of 1 to -6 of the Ryusei vein and their locations in the vein are shown in Fig.2. One sample each also was collected

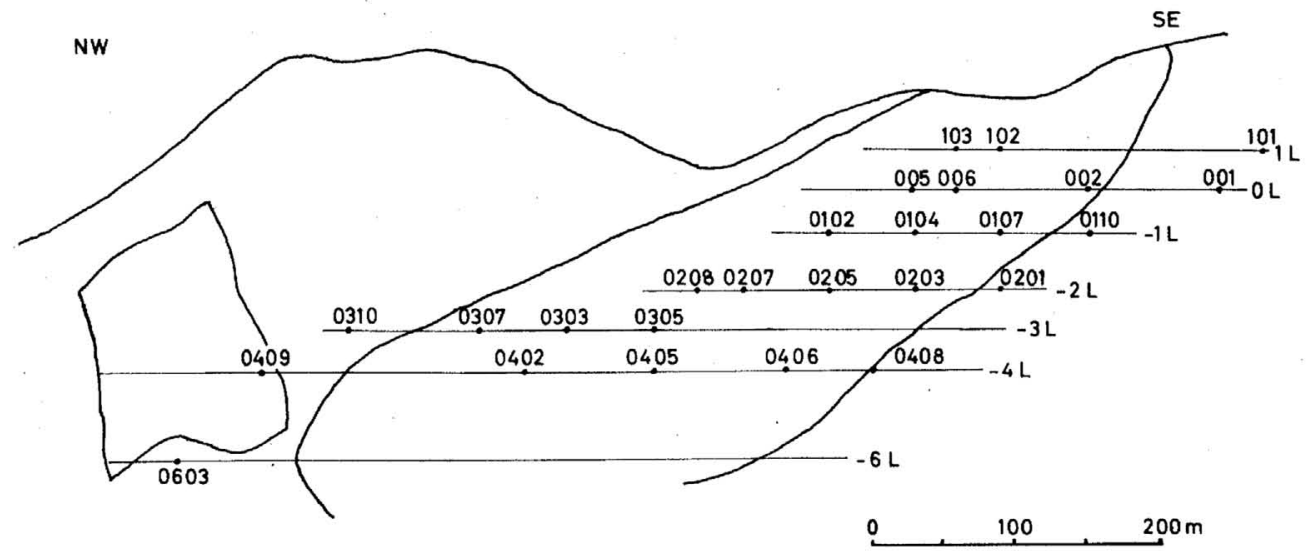

Fig.2. Location of the Ryusei samples. Numbers in the figure must be prefixed by AR for the full sample Nos. 
from the Shirogane and Ginsei veins. The Ginsei vein is located about $600 \mathrm{~m}$ south of the Ryusei vein, and the Shirogane vein about $300 \mathrm{~m}$ east of the Ginsei vein.

Sulfide minerals (chalcopyrite, bornite, sphalerite and galena) were separated from hand specimens by heavy liquid, hand picking and/or a hand magnet. When chalcopyrite and sphalerite coexist, chalcopyrite was purified by decomposing sphalerite in $4 \mathrm{~N} \mathrm{HCl}, \mathrm{H}_{2} \mathrm{~S}$ from the sphalerite being collected for the isotopic analysis.

Isotope analysis of sulfur Sphalerite and galena were attacked by $4 \mathrm{~N} \mathrm{HCl}$, the liberated $\mathrm{H}_{2} \mathrm{~S}$ was captured as $\mathrm{CdS}$, then converted to $\mathrm{Ag}_{2} \mathrm{~S}$. Chalcopyrite and bornite were decomposed by a $\mathrm{HBr}-\mathrm{HNO}_{3}$ mixture and the sulfate in solutions was precipitated as $\mathrm{BaSO}_{4}$ which was converted to $\mathrm{Ag}_{2} \mathrm{~S}$ by the procedure described by THODE et al. (1961). $\mathrm{Ag}_{2} \mathrm{~S}$ obtained was combusted to $\mathrm{SO}_{2}$ at $1,200^{\circ} \mathrm{C}$ in a stream of tank air for the mass spectrometry. The mass spectrometer used for the isotope analysis has been described by SAKaI (1966). The results of the isotope analysis are given in $\delta^{34} \mathrm{~S}$ value as defined by:

$$
\delta^{34} \mathrm{~S}(\% \mathrm{oo})=\left[\left({ }^{34} \mathrm{~S} /{ }^{32} \mathrm{~S}\right)_{\text {sample }} /\left({ }^{34} \mathrm{~S} /{ }^{32} \mathrm{~S}\right)_{\text {standard }}-1\right] \times 1,000 .
$$

The standard is troilite sulfur from the Canyon Diablo meteorite. The uncertainty in $\delta^{34} \mathrm{~S}$ values is less than $\pm 0.2 \%$ in most cases.

\section{REsults AND Discussion}

All the sulfur isotope data obtained are tabulated in Table 1. The variation range of $\delta^{34} \mathrm{~S}$ values for sulfide minerals in the Ryusei vein is graphically shown in Fig. 3, together with those for other Japanese sulfide deposits so far studied.

Distribution of $\delta^{34} S$ values for sulfide minerals in the Ryusei vein $\quad$ Sulfide minerals (mostly chalcopyrite) in the Ryusei vein exhibit a narrow spread in $\delta^{34} \mathrm{~S}$ value ranging from -4.4 to $-0.4 \%$ (Fig. 3 ). Although the spread in $\delta^{34} \mathrm{~S}$ value is similar to those in other Japanese sulfide deposits, the Ryusei sulfide minerals have characteristically lighter $\delta^{34} \mathrm{~S}$ values than others.

Although the over-all variation in $\delta^{34} S$ value for the Ryusei sulfide minerals is narrow, a comparison of the distribution of $\delta^{34} \mathrm{~S}$ values with the vein map does not indicate any relationships between $\delta^{34} \mathrm{~S}$ values of sulfide minerals and their horizontal or vertical distribution in the vein. Furthermore, it is notable that in the specimen, AR 102, which is about $1 \mathrm{~kg}$ in weight, chalcopyrite from one band (AR102-2) has a $\delta^{34} \mathrm{~S}$ value of $-0.8 \%$, which is distinctly higher than the values of chalcopyrite from another band, AR 102-3 $(-2.8 \%)$, and coarse-grained impregnations with quartz, AR 102-4 (-3.1\%). Similar difference is also observed between AR 103-1 and AR1033. These results indicate that the vein sulfide minerals are, though not so much, irregular and inhomogeneous in $\delta^{34} \mathrm{~S}$ value. 
Table 1. $\delta^{34} \mathrm{~S}$ values of sulfide minerals from the Ryusei vein of the Akenobe mine

\begin{tabular}{|c|c|c|c|}
\hline Sample No. & Mineral & $\delta^{34} \mathrm{~S}(\%)$ & Remarks \\
\hline AR101 & $\mathrm{cp}$ & -4.2 & a discontinuous cp band $(3 \sim 10 \mathrm{~mm}$ wide $)$ \\
\hline . & sp & -4.2 & $\begin{array}{l}\text { discontinuous rims }(0.5 \sim 1 \mathrm{~mm} \text { thick }) \text { around the } \mathrm{cp} \\
\text { above }\end{array}$ \\
\hline \multirow{2}{*}{$\begin{array}{r}\mathrm{AR} 102-1 \\
-2\end{array}$} & sp & -0.8 & a sp band $(3 \sim 5 \mathrm{~mm})$ \\
\hline & $\mathrm{cp}$ & -0.8 & $\begin{array}{l}\text { a cp band }(3 \sim 10 \mathrm{~mm}) \text { separated from the } \mathrm{sp} \text { band } \\
\text { above by a quartz band }(3 \sim 5 \mathrm{~mm})\end{array}$ \\
\hline-3 & $\mathrm{cp}$ & -2.8 & $\begin{array}{l}\text { a cp band }(\sim 20 \mathrm{~mm}) \text { separated from the } \mathrm{cp} \text { band } \\
\text { above by a quartz band }(\sim 15 \mathrm{~mm})\end{array}$ \\
\hline-4 & $\mathrm{cp}$ & -3.1 & $\begin{array}{l}\text { coarse-grained impregnations in a quartz band ad- } \\
\text { jacent to the } \mathrm{cp} \text { band above }\end{array}$ \\
\hline AR103-1 & $\mathrm{cp}$ & -0.9 & irregular disseminations in massive magnetite \\
\hline-3 & $\mathrm{cp}$ & -2.8 & $\begin{array}{l}\text { coarse-grained impregnations in a quartz band near } \\
\text { the magnetite above }\end{array}$ \\
\hline AR001 & $\mathrm{cp}$ & -3.7 & irregular impregnations with quartz \\
\hline AR002-1 & cp & -1.2 & a cp band $(\sim 10 \mathrm{~mm})$ \\
\hline-2 & $\mathrm{cp}$ & -1.2 & $\begin{array}{l}\text { medium-grained impregnations in a quartz band ad- } \\
\text { jacent to the cp band above }\end{array}$ \\
\hline AR005 & $\mathrm{cp}$ & -2.7 & massive aggregate of $\mathrm{cp}$ and $\mathrm{sp}$ \\
\hline & $\mathrm{sp}$ & -3.5 & \\
\hline AR006 & $\mathrm{cp}$ & -1.7 & massive aggregate of $\mathrm{cp}$ and $\mathrm{sp}$ \\
\hline & $\mathrm{sp}$ & -4.4 & \\
\hline AR0102 & $\begin{array}{l}\mathrm{cp} \\
\mathrm{sp}\end{array}$ & $\begin{array}{l}-1.6 \\
-1.2\end{array}$ & $\begin{array}{l}\text { irregular impregnations with quartz } \\
\text { discontinuous rims }(0.5 \sim 1 \mathrm{~mm}) \text { around, and irregular } \\
\text { areas in, the cp above }\end{array}$ \\
\hline AR0104, & $\mathrm{cp}$ & -2.5 & massive aggregate \\
\hline AR0107 & $\mathrm{cp}$ & -0.4 & coarse-grained, near margin of the sp band below \\
\hline & sp & -0.5 & a sp band $(\sim 10 \mathrm{~mm})$ \\
\hline AR0110 & cp & -2.8 & massive aggregate \\
\hline AR0201 & $\mathrm{cp}$ & -2.7 & medium- to coarse-grained impregnations with quartz \\
\hline AR0203 & $\mathrm{cp}$ & -0.9 & massive aggregate \\
\hline AR0205 & $\mathrm{cp}$ & -0.6 & massive aggregate \\
\hline AR0207 & $\mathrm{cp}$ & -3.0 & irregular impregnations with quartz \\
\hline AR0208 & $\begin{array}{l}\mathrm{cp} \\
\mathrm{sp}\end{array}$ & $\begin{array}{l}-2.2 \\
-3.8\end{array}$ & $\begin{array}{l}\text { massive aggregate } \\
\text { irregular areas mostly near margin of the } \mathrm{cp} \text { above }\end{array}$ \\
\hline AR0303 & $\mathrm{cp}$ & -1.3 & a cp band $(\sim 20 \mathrm{~mm})$ \\
\hline AR0305 & bn & -0.8 & massive aggregate with $\mathrm{cp}$ and magnetite \\
\hline AR0307 & $\mathrm{cp}$ & -2.1 & a cp band $(\sim 20 \mathrm{~mm})$ \\
\hline AR0310 & $\mathrm{cp}$ & -2.5 & coarse-grained impregnations with quartz \\
\hline AR0402 & $\mathrm{bn}$ & $\begin{array}{l}-2.4 \\
-2.3\end{array}$ & $\begin{array}{l}\text { massive aggregate with } \mathrm{cp} \\
\text { irregular veinlets in the bn above }\end{array}$ \\
\hline AR0405 & $\mathrm{cp}$ & -3.6 & fine- to coarse-grained impregnations with quartz \\
\hline AR0406 & $\mathrm{cp}$ & -2.7 & fine- to coarse-grained impregnations with quartz \\
\hline AR0408 & $\begin{array}{l}\mathrm{cp} \\
\mathrm{sp}\end{array}$ & $\begin{array}{l}-1.2 \\
-2.4\end{array}$ & $\begin{array}{l}\text { coarse-grained, at the margin of the } \mathrm{sp} \text { below } \\
\text { massive aggregate }\end{array}$ \\
\hline
\end{tabular}




\begin{tabular}{cccl}
\hline Sample No. & Mineral & $\delta^{34} \mathrm{~S}(\%)$ & \multicolumn{1}{c}{ Remarks } \\
\hline AR0409 & $\mathrm{sp}$ & -1.2 & coarse-grained impregnations with quartz \\
AR0603 & $\mathrm{cp}$ & -1.2 & medium-grained impregnations with quartz \\
AG0202 & $\mathrm{cp}$ & -2.3 & from the Ginsei vein, massive aggregate of $\mathrm{cp}$ and $\mathrm{sp}$ \\
& $\mathrm{sp}$ & -3.0 & \\
ASI201' & $\mathrm{cp}$ & -1.6 & from the Shirogane vein, aggregate of gn with some \\
& $\mathrm{sp}$ & -2.4 & $\mathrm{cp}$ and sp \\
& $\mathrm{gn}$ & -2.9 & \\
\hline
\end{tabular}

cp: chalcopyrite, sp:sphalerite, bn:bornite and gn: galena.
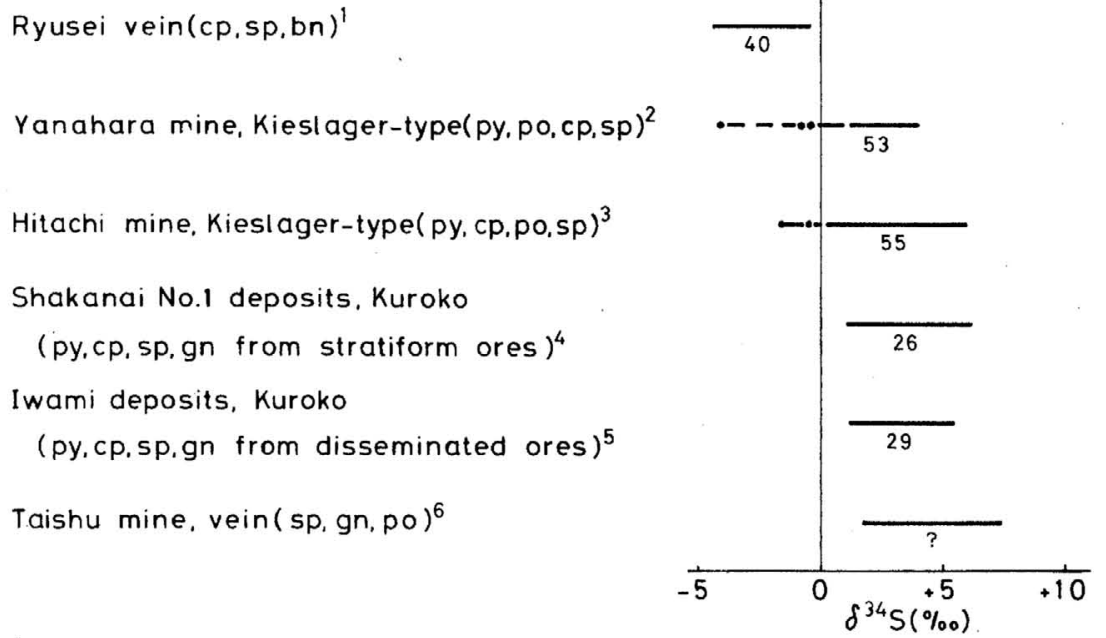

Fig.3. Variation range of $\delta^{34} \mathrm{~S}$ values for sulfide minerals from the Ryusei vein and some other Japanese sulfide deposits. Numbers under bars showing the variation range are those of sulfide samples analyzed isotopically.

References: 1: this paper, 2: Yamamoto et al. (1968), 3: Yamamoto and KaSE (1973), 4: KaJIWARA (1971), 5: YAMAMOTO (1974) and 6: KIYOSU and NAKAI (1971). Abbreviations: py:pyrite, po: pyrrhotite, cp: chalcopyrite, bn: bornite, sp: sphalerite and gn: galena.

Figure 4 indicates that $\delta^{34} \mathrm{~S}$ values of chalcopyrite show a bimodal distribution, having one peak at -3.0 to $-2.5 \%$ and the other at -1.5 to $-0.5 \%$. Although the data are only a few, the distribution of $\delta^{34} S$ values of sphalerite and bornite may also be regarded as bimodal (Fig.4). A possible interpretation may be that chalcopyrite in the Ryusei vein represents at least two different stages of mineralization. It is generally accepted that the Ryusei vein as well as other veins in the Akenobe mine were formed by multiple-stage mineralization (e.g. SAIGuSA, 1958; ABE, 1963; MurAOKA and IKEDA, 1968). Then, the differences in $\delta^{34} \mathrm{~S}$ values between chalcopyrites of different bands and impregnations may reflect changes in the isotopic composition 
of ore-forming solutions with time. Alternatively, such small variations as observed might have resulted from change in the temperature of deposition, the $\mathrm{pH}$ and $\mathrm{f}_{\mathrm{O}_{2}}$ of oreforming solutions, or relative proportion of sulfides precipitated to sulfur-bearing species in aqueous and other phases or combination of these, even if the sulfur isotopic composition of ore-forming solutions remained constant (SAKai, 1968; KaJiwara, 1971; OhmoTO, 1972).

Ore microscopic observations of more than half of the samples show that in most samples chalcopyrite is associated with magnetite, sphalerite and cassiterite in variable amounts and that in some samples chalcopyrite is associated with bornite, chalcocite and/or other $\mathrm{Cu}-\mathrm{S}$ minerals. A comparison of $\delta^{34} \mathrm{~S}$ values of chalcopyrite with kinds and amounts of associated minerals, however,
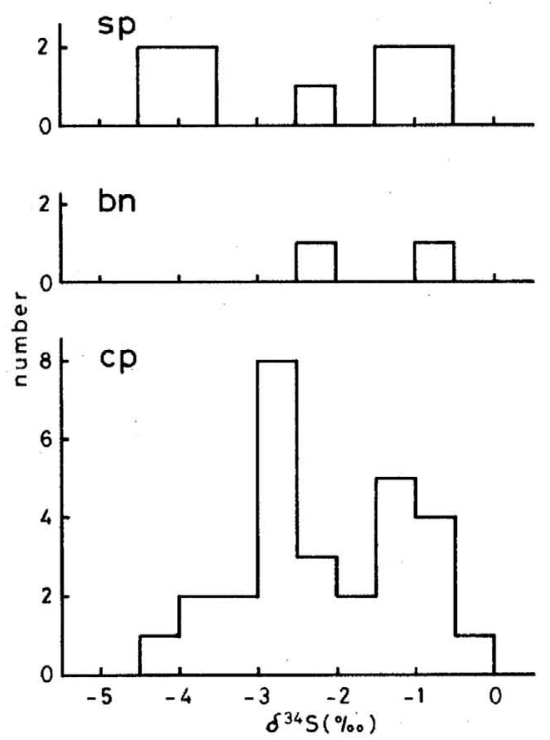

Fig.4. Histograms showing the distribution of $\delta^{34} \mathrm{~S}$ values for the Ryusei chalcopyrite, bornite and sphalerite. shows no distinct correlation between them. This might suggest that the differences in $\delta^{34} \mathrm{~S}$ values of chalcopyrite are ascribed mainly to the variations of the sulfur isotopic ratios of ore-forming solutions.

Difference in $\delta^{34} \mathrm{~S}$ value between sphalerite and chalcopyrite within single hand specimens As is seen from Table 2, in nine samples in which sphalerite and chalcopyrite occur at least in close contact with each other, the difference in $\delta^{34} \mathrm{~S}$ value

Table 2. Difference in $\delta^{34} \mathrm{~S}$ value between coexisting sphalerite and chalcopyrite

\begin{tabular}{lcccc}
\hline Sample No. & $\delta^{34} \mathrm{~S}_{\mathrm{sp}}(\%)$ & $\delta^{34} \mathrm{~S}_{\mathrm{cp}}(\%)$ & $\delta^{34} \mathrm{~S}_{\mathrm{sp}}-\delta^{34} \mathrm{~S}_{\mathrm{cp}}(\%)$ & Type* \\
\hline AR0107 & -0.5 & -0.4 & -0.1 & I \\
AR0408 & -1.2 & -2.4 & -1.2 & I \\
AR005 & -3.5 & -2.7 & -0.8 & II \\
AR006 & -4.4 & -1.7 & -2.7 & II \\
AG0202 & -3.0 & -2.3 & -0.7 & II \\
ASI201 & -2.4 & -1.6 & -0.8 & II \\
AR101 & -4.2 & -4.2 & 0.0 & III \\
AR0102 & -1.2 & -1.6 & +0.4 & III \\
AR0208 & -3.8 & -2.2 & -1.6 & III \\
\hline
\end{tabular}

* See text. 
between two minerals ranges from +0.4 to $-2.7 \%$. Only in a pair of AR0102, sphalerite is heavier than chalcopyrite in $\delta^{34} \mathrm{~S}$ value. In two pairs sphalerite is isotopically close to chalcopyrite, and in the remaining six pairs sphalerite is distinctly lighter than chalcopyrite.

As is described in Table 1, textural relationship between sphalerite and chalcopyrite is not the same for all the samples, and may be classified into three types (Table 2): in type I, chalcopyrite occurs near margin of sphalerite bands or massive aggregates; in type II, sphalerite and chalcopyrite are intimately associated with each other, showing irregular boundaries between them; type III pairs are those in which sphalerite occurs as rims around, or near margin of, chalcopyrite. However, no definite correlation can be observed between the difference in $\delta^{34} \mathrm{~S}$ value and the textural relationship. Because sphalerite is heavier than chalcopyrite in equilibrium at all temperatures (SAKAI, 1968; KaJiwara and Krouse, 1971), the present results indicate that, except for AR0102, all the sphalerite-chalcopyrite pairs are not in the isotopic equilibrium. This is in accord with the mode of occurrence of types I and III pairs. But disequilibrium is rather surprising for type II pairs, because simultaneous precipitation of sphalerite and chalcopyrite is suggested from the texture of this type of samples. It may be that in type II pairs also deposition of two minerals was actually not simultaneous. Alternatively, it may be that a kinetic isotopic effect was more important than exchange equilibrium during the deposition of sulfide from sulfur-poor oreforming solutions.

Speculation of the sulfur isotopic ratios of the ore-forming solutions From the examination of the stability relations among minerals in the Fe-S-O system in $\mathrm{f}_{2}-\mathrm{pH}$ diagrams, Онмото (1972) has suggested that sulfide minerals which were precipitated in equilibrium with magnetite, hematite, or sulfate minerals could have $\delta^{34} \mathrm{~S}$ values markedly different from those of ore-forming solutions.

As mentioned previously, iron sulfides such as pyrite and pyrrhotite are absent and magnetite is the only mineral that occurs in the Fe-S-O system of the Ryusei vein. Most chalcopyrites are associated with magnetite; magnetite occurs as fine granules in chalcopyrite or massive aggregate disseminated by chalcopyrite.

Based on the assumption that the Ryusei chalcopyrite and magnetite were deposited simultaneously from ore-forming solutions in chemical and isotopic equilibrium, a similar examination as in Онмото (1972) of the stability field of the chalcopyrite-magnetite assemblage in the $\mathrm{Cu}-\mathrm{Fe}-\mathrm{S}-\mathrm{O}$ system could place some limits to sulfur isotopic ratios of ore-forming solutions.

The stability relations of minerals in the Cu-Fe-S-O system in $\mathrm{NaCl}$ solution was recently studied thermodynamically by SATO (1972). Figures 5a and 5b are modifications of the $\mathrm{f}_{\mathrm{O}_{2}}-\mathrm{pH}$ diagram of the system constructed by SATo (1972) using the thermodynamic data of Helgeson (1969). Figure 5a shows stability relations among 


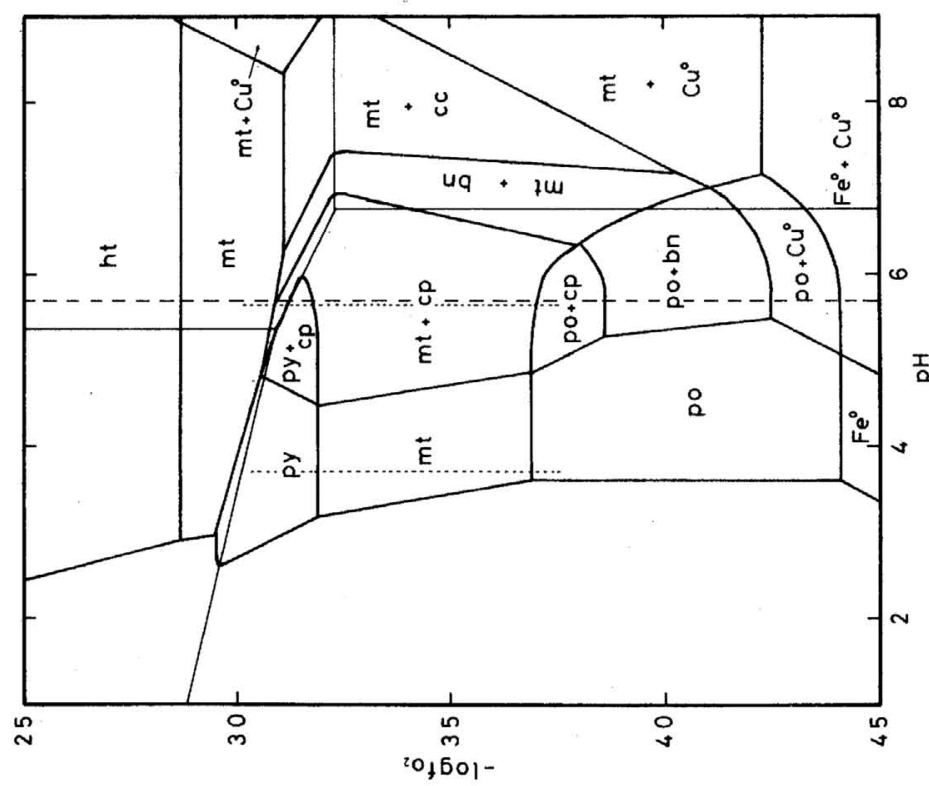

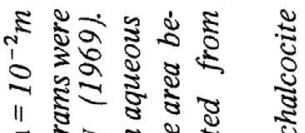

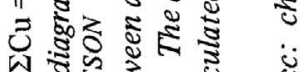
है है

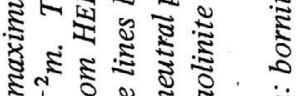

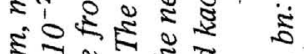

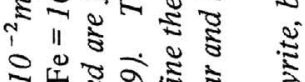
인 ผ

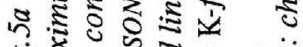

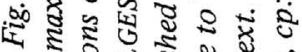

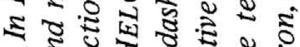

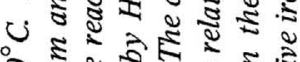

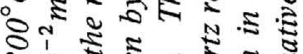
mis

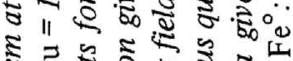

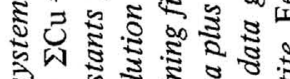
के के

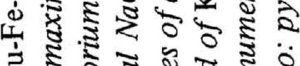

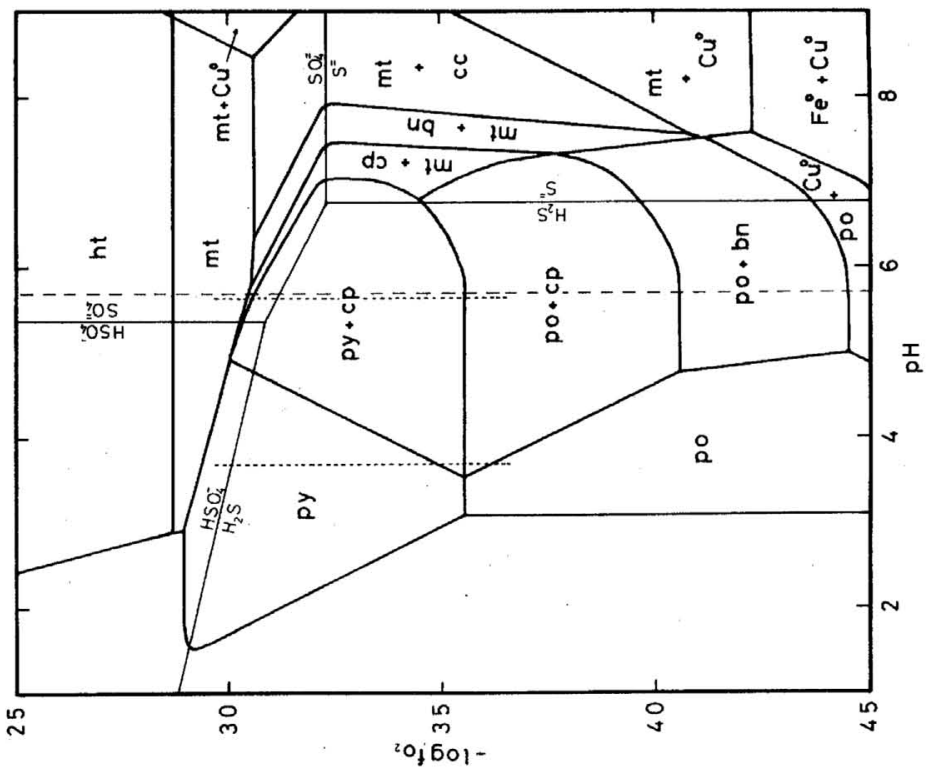

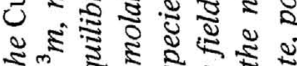
ॠ

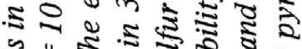

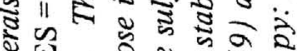
ङ

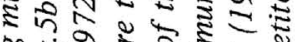

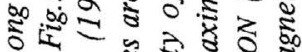

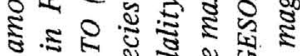
इ ॠ

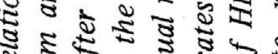

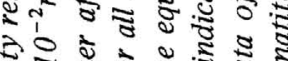

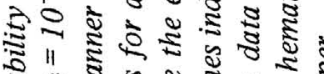

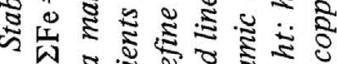

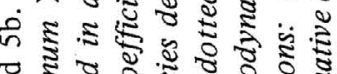

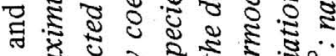

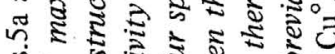

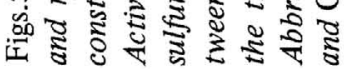


minerals in 3 molal $\mathrm{NaCl}$ solution at $300^{\circ} \mathrm{C}$ when total dissolved sulfur is $10^{-2}$ molal, and the maximum total dissolved copper and iron are $10^{-2} \mathrm{~m}$ each. In Fig. $5 \mathrm{~b}$ total dissolved sulfur is diminished to $10^{-3} \mathrm{~m}$, other variables holding the same values as those in Fig.5a. The molality of each dissolved species is chosen arbitrarily. The temperature, $300^{\circ} \mathrm{C}$, at which the diagrams are constructed, is also rather arbitrary, since no data are available on the temperatures of mineralization for the Ryusei vein. However, in the Yonmyaku and Nanamyaku veins in the western area, TAKAHASHI et al. (1955) obtained $300 \sim 350^{\circ} \mathrm{C}$ for the temperatures of mineralization by the decrepitation method.

The diagrams show that when $\Sigma S=10^{-2} m$ (Fig.5a) the chalcopyrite-magnetite assemblage is stable in the small area laid across the $\mathrm{HSO}_{4}^{-}, \mathrm{SO}_{4}^{-}$and $\mathrm{S}^{-}$fields, while when $\Sigma \mathrm{S}=10^{-3} \mathrm{~m}$ (Fig. $5 \mathrm{~b}$ ) the stability field of the assemblage expands into the $\mathrm{H}_{2} \mathrm{~S}$ field, covering small areas in the $\mathrm{HSO}_{4}^{-}, \mathrm{SO}_{4}^{-}$and $\mathrm{S}^{-}$fields owing to the disappearance of the pyrite-pyrrhotite boundary. These features are, of course, pertinent to the particular set of variables as given above. However, from the diagrams at lower temperatures and varying molality of each dissolved species, it can be said, in general, that sulfur-poor chloride solutions have a much wider stability field for chalcopyritemagnetite assemblage than sulfur-rich solutions, and the stability field lies mostly within the $\mathrm{H}_{2} \mathrm{~S}-\mathrm{HS}^{-}$fields.

Combining available equilibrium sulfur isotopic fractionation factors among various aqueous sulfur species and chalcopyrite (SAKAI, 1968; KAJIWARA and KrouSE, 1971) with the features of the stability field of the chalcopyrite-magnetite assemblage obtained above, we may state as follows:

(1) If chalcopyrite and magnetite were deposited from sulfur-rich ore-forming solutions in the $\mathrm{HSO}_{4}^{-}$and $\mathrm{SO}_{4}^{=}$fields, the ore-forming solutions would have had $\delta^{34} \mathrm{~S}$ values markedly higher than those obtained for chalcopyrite. The difference in $\delta^{34} \mathrm{~S}$ value between ore-forming solutions and chalcopyrite would be, for example, up to $25 \%$ at $300^{\circ} \mathrm{C}$.

(2) If chalcopyrite and magnetite were deposited from sulfur-rich solutions in the $\mathrm{HS}^{-}$and $\mathrm{S}^{=}$fields, the ore-forming solutions would have had $\delta^{34} \mathrm{~S}$ values similar to or slightly lower than those for chalcopyrite. The difference would be, for example, in the range from 1 to $-3 \%$ at $300^{\circ} \mathrm{C}$.

(3) If chalcopyrite and magnetite were deposited from sulfur-poor solutions in the $\mathrm{HSO}_{4}^{-}$and $\mathrm{SO}_{4}^{-}$fields, a situation similar to case (1) would be expected.

(4) If chalcopyrite and magnetite were deposited from sulfur-poor solutions in the $\mathrm{H}_{2} \mathrm{~S}$ and $\mathrm{HS}^{-}$fields, the ore-forming solutions would have had $\delta^{34} \mathrm{~S}$ values slightly higher than those for chalcopyrite. The difference would be, for example, up to $2 \%$ at $300^{\circ} \mathrm{C}$.

The author would choose case (4) in preference to any others as the plausible situation of deposition of the Ryusei chalcopyrite from the following reasons: 
(1) The significant types of alteration of wall rocks in the Akenobe mine are silicification, chloritization and sericitization (IKEDA, 1970). The occurrence of sericite with quartz suggests that $\mathrm{pH}$ of the ore-forming solutions was in the range from weakly acid to neutral, if the salinity and $\mathrm{K} / \mathrm{Na}$ ratio of the ore-forming solutions are assumed to have been in the range from 2 to $10 \mathrm{NaCleq}$. wt. $\%$ and in the range from 0.2 to 0.4 , respectively (Figs. $5 \mathrm{a}$ and $5 \mathrm{~b}$ ). Both of the ranges are those observed for fluid inclusions in some Japanese plutonic vein deposits (ENJOJI, 1972).

(2) If chalcopyrite had deposited with magnetite in the sulfate field, a slight variation in $\mathrm{pH}$ and/or $\mathrm{f}_{\mathrm{O}_{2}}$ of the ore-forming solutions would have drastically affected the $\delta^{34} \mathrm{~S}$ value of sulfide (Онмото, 1972). On the contrary, $\delta^{34} \mathrm{~S}$ values of chalcopyrite are stable around $0 \sim-5 \%$. In addition, a slight decrease in $\mathrm{pH}$ and/or $\mathrm{f}_{\mathrm{O}_{2}}$ of the ore-forming solutions would have made the chalcopyrite-pyrite assemblage stable instead of the chalcopyrite-magnetite assemblage. The former assemblage is absent in the Ryusei vein.

\section{CONCLUSIONS}

1) Ryusei sulfide minerals (mostly chalcopyrite) exhibit a narrow spread in $\delta^{34} \mathrm{~S}$ value, which is comparable to those in other Japanese sulfide deposits so far studied. However, they are distinguished from others by their low $\delta^{34} \mathrm{~S}$ values (Fig.3).

2) Any definite correlation cannot be observed between $\delta^{34} S$ values for sulfides and their locations in the vein.

3) $\delta^{34} \mathrm{~S}$ values for the Ryusei chalcopyrite show a bimodal distribution.

4) A possible interpretation of the features 2) and 3) may be that chalcopyrite was deposited in at least two different stages of mineralization in the Ryusei vein.

5) Most sphalerite-chalcopyrite pairs are isotopically in disequilibrium. This may be ascribed to non-simultaneous deposition of the two minerals.

6) The assumption that the Ryusei chalcopyrite plus magnetite were deposited in the chemical and isotopic equilibrium from the ore-forming solutions, coupled with some suggestive information on the depositional conditions, leads to the conclusion that the sulfur isotopic ratios of the ore-forming solutions were rather similar to those obtained for chalcopyrite.

\section{ACKNOWLEDGMENTS}

I am deeply indebted to Prof. H. SAKAI of the Thermal Spring Research Institute, Okayama University, for his critical reading of the manuscript and helpful advice in the mass spectrometry. Thanks are also due to Messrs. S. IKEDA and T. OHMAE of the Mitsubishi Metal Mining Co., Ltd. for their kind help in collecting samples, and Messrs. K. KASE and N. W ADA of Okayama University for their kind guidance and help in microscopic observations of ore samples.

\section{REFERENCES}

ABE, M. (1963) Zonal distribution of ore deposits at Akenobe mine. Kozanchishitsu (Mining 
Geology) 13, 41-53 (in Japanese).

EnJojI, M. (1972) Studies on fluid inclusions as the media of the ore formation. Sci. Rept. of the Tokyo Kyoiku Daigaku, Section C (Geography, Geology and Mineralogy). 11, 79-126.

HELGESON, H. C. (1969) Thermodynamics of hydrothermal systems at elevated temperatures and pressures. Am. J. Sci. 267, 729-804.

IKEDA, S. (1970) Zonal distribution and the exploration at the Akenobe mine. Kozanchishitsu (Mining Geology) 20, 114-124 (in Japanese).

IMAI, H., KIM, M. S. and FUJIKI, Y. (1972) Geologic structure and mineralization of the hypothermal or pegmatitic tungsten vein-type deposits at the Ohtani and Kaneuchi mines, Kyoto Prefecture, Japan. ibid. 22, 371-381 (in Japanese).

ISHIHARA, S. and SHIBATA, K. (1972) Re-examination of the metallogenic epoch of the IkunoAkenobe province in Japan. ibid. 22, 67-73.

KAJIWARA, Y. (1971) Sulfur isotope study of the Kuroko-ores of the Shakanai No.1 deposits, Akita Prefecture, Japan. Geochem. J. 4, 157-181.

KAJIWARA, Y. and KRouSE, H. R. (1971) Sulfur isotopic partitioning in metallic sulfide systems. Can. J. Earth Sci. 8, 1397-1408.

KIYOSU, Y. and NAKAI, N. (1971) Sulfur isotopes in vein-type hydrothermal deposits. Ann. Mtg. Geochem. Soc. Japan, abstract p. 15B13 (in Japanese).

KoJIMA, Y. and ASADA, I. (1973) The Akenobe ore deposits---their geologic structure and fracture. Kozanchishitsu (Mining Geology) 23, 137-151 (in Japanese).

MURAOKA, N. and IKEDA, S. (1968) Recent geologic exploration and development of the Akenobe mine. ibid. 18, 79-91 (in Japanese).

NAKAMURA, T. and HUNAHASHI, M. (1970) Ore veins of Neogene volcanic affinity in Japan. Volcanism and ore genesis, ed. T. TATSUMI, University of Tokyo Press, 215-230.

Онмото, H. (1972) Systematics of sulfur and carbon isotopes in hydrothermal ore deposits. Econ. Geol. 67, 551-578.

SAIGUSA, M. (1958) Geology and mineralization of the Akenobe mine, Hyogo Prefecture, Japan. Kozanchishitsu (Mining Geology) 8, 218-238 (in Japanese).

SAKAI, H. (1966) Mass spectrometer systems for the isotope ratio of volatile elements. Mass Spectroscopy 14, 72-77.

SAKAI, H. (1968) Isotopic properties of sulfur compounds in hydrothermal processes. Geochem. J. 2, 29-49.

SATO, T. (1972) Solubility of minerals in the Cu-Fe-S-O system based on a chloride complex model and its interpretation. Koshogaku Note (Note on Ore Deposits) No.11,1-9 (in Japanese).

Takahashi, T., TAKenOuChI, S., Nishio, S. and IMAI, H. (1955) Temperatures of mineral formation in some types of deposits in Japan, as measured by the decrepitation method (II) Kozanchishitsu (Mining Geology) 5, 9-17 (in Japanese).

THODE, H. G., Monster, J. and Dunford, H. B. (1961) Sulfur isotope geochemistry. Geochim. Cosmochim. Acta 25, 565-578.

Yамамото, M. (1974) Distribution of sulfur isotopes in the Iwami Kuroko deposits, Shimane Prefecture, Japan. Geochem. J. 8, 27-35.

YAMAMOTO, M. and KASE, K. (1973) Sulfur isotope ratios of sulfide minerals from the Hitachi mine, Ibaraki Prefecture. Ann. Mtg. Geochem. Soc. Japan, abstract, p. 129 (in Japanese).

YAMAmoto, M., OGUSHI, N. and SAKAI, H. (1968) Distribution of sulfur isotopes, selenium and cobalt in the Yanahara ore deposits, Okayama-Ken, Japan: Geochem. J. 2, 137-156. 